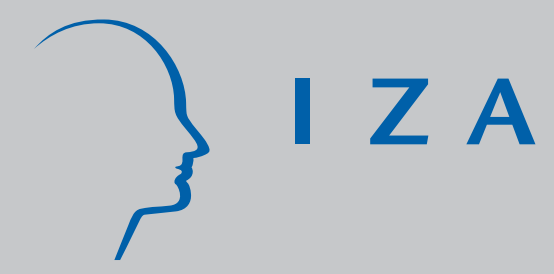

IZADP No. 2130

On the Identification of Frisch Labor Supplies

Olivier Donni

May 2006 


\title{
On the Identification of Frisch Labor Supplies
}

\author{
Olivier Donni
}

THEMA, Université de Cergy-Pontoise

and IZA Bonn

Discussion Paper No. 2130

May 2006

IZA

P.O. Box 7240

53072 Bonn

Germany

Phone: +49-228-3894-0

Fax: +49-228-3894-180

Email: iza@iza.org

\begin{abstract}
Any opinions expressed here are those of the author(s) and not those of the institute. Research disseminated by IZA may include views on policy, but the institute itself takes no institutional policy positions.

The Institute for the Study of Labor (IZA) in Bonn is a local and virtual international research center and a place of communication between science, politics and business. IZA is an independent nonprofit company supported by Deutsche Post World Net. The center is associated with the University of Bonn and offers a stimulating research environment through its research networks, research support, and visitors and doctoral programs. IZA engages in (i) original and internationally competitive research in all fields of labor economics, (ii) development of policy concepts, and (iii) dissemination of research results and concepts to the interested public.
\end{abstract}

IZA Discussion Papers often represent preliminary work and are circulated to encourage discussion. Citation of such a paper should account for its provisional character. A revised version may be available directly from the author. 
IZA Discussion Paper No. 2130

May 2006

\section{ABSTRACT}

\section{On the Identification of Frisch Labor Supplies}

This paper examines how Frisch labor supplies, and other structural components of the intertemporal model of labor supply, can be recovered from estimates obtained with the approach developed by Heckman and MaCurdy.

JEL Classification: J22

Keywords: $\quad$ labor supply, Frisch, life cycle, identification

Corresponding author:

Olivier Donni

University of Cergy-Pontoise

33, Boulevard du Port

95011 Cergy-Pontoise Cedex

France

Email: olivier.donni@eco.u-cergy.fr 


\section{Introduction}

The number of empirical studies that aim at estimating the responsiveness of hours of work to life-cycle changes in the wage is considerable. In these studies, the worker's utility function is generally supposed to be intertemporally additive. In that case, the concept of Frisch (or $\lambda$-constant) labor supplies - which relates worked hours to the current wage and the marginal utility of money $\lambda$ - plays a major role because its interpretation is straightforward. One problem in the empirical implementation of this concept, however, is that the marginal utility of money is not directly observable. The traditional approach, developed by Heckman and MaCurdy (1980) and MaCurdy (1981), consists thus in estimating a transformation of the initial Frisch labor supplies from which the marginal utility of money is eliminated.

The Heckman-MaCurdy approach has turned to be very profitable, as illustrated by its numerous applications and extensions (Browning, Deaton and Irish, 1985; Hotz and Miller, 1988; Bover, 1989; Altonji and Ham, 1990; Altig and Carlstrom, 1999; Zilliak and Kniesner, 1999; Pencavel, 2002; and many others). However, the possibility to recover the main characteristics of Frisch labor supplies from estimates obtained with this approach has not been completely examined until now. In the present note, we thus suppose that the Heckman-MaCurdy approach is implemented and show that (i) the marginal utility of money is identified up to a multiplicative constant, (ii) for each choice of this constant, Frisch labor supplies are exactly identified, (iii) worker's sub-utility functions are identified up to an affine transformation. 


\section{Model and Results}

Frisch Labor Supplies. We consider a person who makes decisions about her intertemporal allocation of labor and consumption. There is no uncertainty and the person is characterized by the following intertemporally additive utility function:

$$
U=\sum_{t=1}^{T} u_{t}\left(h_{t}, c_{t}\right)
$$

where $T$ is the planning horizon, $h_{t}$ the labor supply at period $t$ and $c_{t}$ the consumption at period $t$. The sub-utility functions are twice differentiable and strictly concave in all their arguments. The intertemporal budget constraint is given by

$$
\sum_{t=1}^{T}(1+r)^{-t}\left(h_{t} w_{t}-c_{t}\right)=0
$$

where $r$ is the interest rate, ${ }^{1}$ and $w_{t}$ the wage at period $t$. If the solution is interior, the first order conditions are:

$$
\begin{aligned}
\partial u_{t} / \partial h_{t} & =\lambda R^{t} w_{t} \\
\partial u_{t} / \partial c_{t} & =\lambda R^{t}
\end{aligned}
$$

where $R^{t}=(1+r)^{-t}$ and $\lambda$ is the Lagrange multiplier that corresponds to the intertemporal budget constraint. This multiplier can be interpreted as the marginal utility of money at period 1 for a cardinalization such that the

\footnotetext{
${ }^{1}$ To simplify notation, we suppose that the interest rate is the same for each period. The generalization to a rate that differs from one period to another is trivial.
} 
utility function is intertemporally additive. Solving these equations gives the Frisch labor supply at period $t$ :

$$
h_{t}=f_{t}\left(w_{t}, \lambda R^{t}\right)
$$

In particular, if leisure at period $t$ is normal, we have:

$$
\frac{\partial f_{t}\left(w_{t}, \lambda R^{t}\right)}{\partial\left(\lambda R^{t}\right)}>0
$$

In the result that follows, we suppose that this property is always satisfied.

Identification. The marginal utility of money $\lambda$ is not directly observed by the economist. Hence, the estimation of Frisch labor supplies necessitates a specific technique that exploits longitudinal data. The idea of Heckman and MaCurdy can basically be described as follows. ${ }^{2}$ To begin with, we write the Frisch labor supply at period $s(s \neq t)$ :

$$
h_{s}=f_{s}\left(w_{s}, \lambda R^{s}\right)
$$

If condition (4) is satisfied, this expression can be inverted with respect to $\lambda$. We obtain:

$$
\lambda=R^{-s} \cdot g_{s}\left(w_{s}, h_{s}\right)
$$

Thus, the marginal utility of money is expressed as a function of the interest rate, the wage and the labor supply at period $s$. We introduce this expression

\footnotetext{
${ }^{2}$ In its initial formulation, the Heckman-MaCurdy approach was simpler. The marginal utility of money was supposed to be additively separable from the other components of the model and was then interpreted as the "fixed effect" of a linear regression.
} 
in (3). This gives:

$$
\begin{aligned}
h_{t} & =f_{t}\left(w_{t}, R^{t-s} \cdot g_{s}\left(w_{s}, h_{s}\right)\right) \\
& =f_{t s}^{*}\left(w_{t}, w_{s}, h_{s}, r\right)
\end{aligned}
$$

where $R^{t-s}=(1+r)^{s-t}$. By comparison with the traditional formulation of the Frisch labor supplies, the function $f_{t s}^{*}(\cdot)$ can be directly estimated. ${ }^{3}$

We can now present the following identification result.

PROPOSITION. Suppose that leisure at period $t$ and $s$ is normal. If the economist observes $f_{t s}^{*}\left(w_{t}, w_{s}, h_{s}, r\right)$, then

(i) The marginal utility of money $(\lambda)$ is identified up to a multiplicative constant;

(ii) For each choice of this constant, the Frisch labor supplies $\left(f_{t}\left(w_{t}, \lambda R^{t}\right)\right.$, $\left.f_{s}\left(w_{s}, \lambda R^{s}\right)\right)$ are exactly identified;

(iii) The sub-utility functions $\left(u_{t}\left(h_{t}, c_{t}\right), u_{s}\left(h_{s}, c_{s}\right)\right)$ are identified up to an affine transformation.

\footnotetext{
${ }^{3}$ Formally, the function $f_{t s}^{*}(\cdot)$ is a m-labor supply, the properties of which are studied by Browning (1999) in a slightly different context.
} 
Proof. If we differentiate (5) and (6) with respect to $r, w_{s}$ and $h_{s}$, we obtain:

$$
\begin{aligned}
\frac{\partial f_{t s}^{*}}{\partial r} & =\frac{\partial f_{t}}{\partial\left(\lambda R^{t}\right)} g_{s}(s-t)(1+r)^{-1} R^{t-s}, \\
\frac{\partial f_{t s}^{*}}{\partial w_{s}} & =\frac{\partial f_{t}}{\partial\left(\lambda R^{t}\right)} \frac{\partial g_{s}}{\partial w_{s}} R^{t-s}, \\
\frac{\partial f_{t s}^{*}}{\partial h_{s}} & =\frac{\partial f_{t}}{\partial\left(\lambda R^{t}\right)} \frac{\partial g_{s}}{\partial h_{s}} R^{t-s} .
\end{aligned}
$$

Solving (7) to (9) gives the derivatives of the logarithm of the marginal utility of money:

$$
\begin{aligned}
& \frac{\partial \ln g_{s}}{\partial w_{s}}=\frac{1}{g_{s}} \frac{\partial g_{s}}{\partial w_{s}}=\frac{s-t}{1+r} \frac{\partial f_{t s}^{*} / \partial w_{s}}{\partial f_{t s}^{*} / \partial r}, \\
& \frac{\partial \ln g_{s}}{\partial h_{s}}=\frac{1}{g_{s}} \frac{\partial g_{s}}{\partial h_{s}}=\frac{s-t}{1+r} \frac{\partial f_{s t}^{*} / \partial h_{s}}{\partial f_{s t}^{*} / \partial r},
\end{aligned}
$$

where the right-hand-sides of the second equalities are observed (note that $\partial f_{s t}^{*} / \partial r \neq 0$ because leisure is supposed to be normal). From these equations, the marginal utility of money is defined up to a multiplicative, positive constant. More precisely, if $\hat{\lambda}$ is a particular solution to the system (10)-(11), then the general solution is of the form $\lambda=k \hat{\lambda}$ where $k>0$ is an arbitrary constant. There are two additional consequences.

1. For each choice of the constant $k$, the Frisch labor supply $f_{t}\left(w_{t}, \lambda R^{t}\right)$ is exactly identified.

2. From the first order conditions (1) and (2), the derivatives of the subutility function $u_{t}\left(h_{t}, c_{t}\right)$ are defined up to a multiplicative constant (which is equal to $k$ ). Hence, the sub-utility function $u_{t}\left(h_{t}, c_{t}\right)$ is identified up to an affine transformation. More precisely, if $\hat{u}_{t}$ is a particular 
solution to the system (1) and (2), then the general solution is of the form: $u_{t}=a+b \hat{u}_{t}$, where $a$ and $b(=k)$ are arbitrary constants.

Finally, from $h_{t}=f_{t s}^{*}\left(w_{t}, w_{s}, h_{s}, r\right)$, we can obtain $h_{s}=f_{s t}^{*}\left(w_{s}, w_{t}, h_{t}, r\right)$ by simple inversion with respect to $h_{s}$. Thus, the sub-utility function $u_{s}\left(h_{s}, c_{s}\right)$ is similarly identified up to an affine transformation. Q.E.D.

The intuition behind this result relies on the fact that the worker's behavior at period $t$ can be written as a function of the current wage and a logarithmic term: $\ln \lambda+\ln (1+r)^{s-t}$. Since the marginal utility of money does vary if either the wage or the labor supply at period $s$ changes, any simultaneous change in the interest rate and the wage (or the labor supply) at period $s$ that leave the labor supply at period $t$ constant must keep the term $\ln \lambda+\ln (1+r)^{s-t}$ constant as well. From this idea, it is possible to compute the variation in the logarithm of the marginal utility of money due to an infinitesimal change in the wage (or the labor supply) at period $s$. The integration of these expressions gives the marginal utility of money up to a multiplicative constant. The identification of other components then follows. We shall conclude with two comments.

1. Even if it is not explicit in the statement of the result, it is clear that the function $f_{t s}^{*}(\cdot)$ has a specific structure. For instance, the ratio

$$
\frac{\partial f_{t s}^{*} / \partial h_{s}}{\partial f_{t s}^{*} / \partial w_{s}}=\frac{\partial g_{s} / \partial h_{s}}{\partial g_{s} / \partial w_{s}}
$$

must be independent of $w_{t}$ and $h_{t}$. This property allows the economist to test the additivity of the utility function. 
2. The result is based on the implicit assumption that the interest rate is observable and variable. Often, economists prefer to suppose that the interest rate is constant and unobservable. That implies the identification is not complete. However, some interesting information can be retrieved. For example, expression (12) indicates that the indifference curves of the marginal utility of money can be identified. Consequently, the marginal utility of money is identified up to an increasing transformation.

\section{References}

[1] Altig David and Charles T. Carlstrom, 1999, "Marginal Tax Rates and Income Inequality in a Life-Cycle Model", American Economic Review, vol. 89 , pp. $1197-1215$.

[2] Altonji Joseph G. and John C. Ham, 1990, "Intertemporal Substitution, Exogeneity and Surprises: Extimating Life-Cycle Models for Canada", Canadian Journal of Economics, vol. 23, pp. 1-43.

[3] Bover Olympia, 1989, "Estimating Intertemporal Labour Supply Elasticites Using Structural Model", Economic Journal, vol. 99, pp. 10261039.

[4] Browning Martin, 1999, "Modelling Commodity Demands and Labour Supply with m-Demands", working paper, University of Copenhagen. 
[5] Browning Martin, Angus Deaton and Margaret Irish, 1985, "A Profitable Approach to Labor Supply and Commodity Demands over the Life-Cycle", Econometrica, vol. 53, pp. 503-543.

[6] Heckman James and Thomas McCurdy, 1980, "A Life-Cycle Model of Female Labour Supply", Review of Economic Studies, vol. 47, pp. 47-74.

[7] Hotz Joseph V. and Robert A. Miller, "An Empirical Analysis of Fertility and Female Labor Supply", Econometrica, vol. 56, pp. 91-118.

[8] MaCurdy Thomas, 1981, "An Empirical Model of Labor Supply in a Life-Cycle Setting", Journal of Political Economy, vol. 89, pp. 10591085.

[9] Pencavel John, 2002, "A Cohort Analysis of the Association between Work Hours and Wages among Men", Journal of Human Resources, vol. 37 , pp. 251-274.

[10] Zilliak James P. and Thomas J. Kniesner, 1999, "Estimating Life-Cycle Labor Supply with Tax Effects", Journal of Political Economy, vol. 107, pp. 326-359. 